\title{
Coordenação e controlo de movimentos musicais e desportivos: visão dinâmica da cognição e ação
}

\author{
Coordination and control of musical and sports movements: \\ a dynamic perspective of cognition and action
}

\author{
Gonçalo Dias ${ }^{1}$ \\ ${ }_{1}^{1}$ Faculdade de Ciências do Desporto e Educação Física, Universidade de Coimbra, Coimbra, \\ Portugal. \\ goncalodias@fcdef.uc.pt
}

\section{Resumo:}

Este artigo estuda a coordenação e controlo de movimentos desportivos e musicais emergindo essencialmente da ação do executante, da tarefa e do envolvimento onde esta tem lugar. Para tal, numa visão dinâmica, conclui-se que o cérebro é apenas mais um elemento no controlo deste processo, não tendo nenhum papel hierarquicamente dominante.

Palavras-chave: música e desporto; movimento e coordenação motora; comportamento motor.

\begin{abstract}
:
This article aims at showing that the coordination and control of musical and sports movements emerge essentially from the performer's action, the task and the surrounding environments. In a dynamic perspective, one concludes that the brain is only one of the many components in this control process, not playing a hierarchically dominant role.
\end{abstract}

Keywords: music and sports; movement and coordination; motor control.

Data de recebimento: 04/10/2014

Data de aprovação final: 19/09/2015 


\section{1 - Introdução}

Tendo como pano de fundo o exemplo do Jazz, autores como CORREIA, BARREIROS e PASSOS (2013) enquadraram recentemente a aprendizagem e o desempenho de habilidades musicais como veículo privilegiado de exploração das possibilidades de ação do nosso corpo. Estes autores indicam que, à semelhança de vários movimentos desportivos, o domínio de um código musical abrange as capacidades cognitivas e motoras de cada executante, sendo estas bastante diferenciadas de indivíduo para indivíduo em função das suas caraterísticas psicológicas, morfológicas e funcionais.

Dependendo do instrumento a executar, o músico, tal como o desportista, tem que usar o seu corpo de diferentes formas para explorar as affordances ${ }^{1}$ que o envolvimento oferece. Por exemplo, o pianista deve ser ágil no modo como usa os dedos para tocar piano, adotando diferentes velocidades de execução face às músicas que desempenha. Esta manipulação do instrumento "constrange-o" a calibrar e afinar as suas capacidades motoras às necessidades de execução, que variam de contexto para contexto (PALMER, 2006; LAGE, BORÉM, VIEIRA, BARREIROS, 2007). Os mesmos pressupostos podem ser aplicados ao jogador de golfe que tem que "moldar" as suas mãos ao taco ao longo da sua aprendizagem motora, imprimindo assim maior ou menor velocidade de execução no desempenho deste movimento, isto consoante está mais perto ou afastado do buraco (DIAS, COUCEIRO, BARREIROS, CLEMENTE, MENDES, MARTINS, 2014).

Perante o exposto, a área de Comportamento Motor pode ser útil para desmontar este "puzzle" que reúne várias peças de investigação do contexto musical e desportivo (TANI, 2005). Tal como foi demonstrado por DIAS, MENDES e MENDES (2013), os apologistas desta área têm contribuído decisivamente para a resolução de problemas de investigação que estão associados às Ciências do Desporto e ao Treino Desportivo, sobretudo no que se refere à análise da aprendizagem e desempenho de habilidades motoras. Nesta base, este trabalho

\footnotetext{
${ }^{1}$ As affordances representam, neste contexto, as possibilidades de ação que o envolvimento oferece aos músicos. Por exemplo, numa banda de Rock, se o baterista acelerar o ritmo da música, os restantes executantes tendem a acompanhar essa ação mais rapidamente.
} 
tem como objetivo principal mostrar que a coordenação e controlo de movimentos desportivos e musicais emergem essencialmente da ação do executante, da tarefa e do envolvimento onde esta tem lugar. Para tal, numa visão dinâmica, o cérebro é apenas mais um elemento no controlo deste processo, não tendo nenhum papel hierarquicamente dominante.

\section{2 - "Problema" dos graus de liberdade}

O estudo de LAGE, BORÉM, BENDA e MORAES (2002) enquadra o significado de "habilidade musical" e em que medida este influi no comportamento motor e na biomecânica do executante. Para os mesmos autores, é necessário aprofundar os mecanismos de controlo motor que estão associados à prática instrumental, de modo a perceber os aspetos relacionados com a afinação e fadiga muscular. Também as componentes de índole técnica, como a postura corporal, prestação vocal, projeção do som e as componentes de expressão musical (sonoridade e ritmo) são referidos na sua revisão de estudos, onde ainda se descreve as valências do electrocefalograma (EEG) na avaliação da atividade cerebral durante a aprendizagem e prática musical, assim como da electromiografia (EMG) nos processos musculares envolvidos na execução deste tipo de movimentos.

Os graus de liberdade do corpo humano, que abrangem o número de configurações possíveis na execução de um determinado movimento, podem constranger ou tornar mais eficaz a ação de uma determinada habilidade musical ou desportiva. Neste sentido, o neurofisiologista Nicolai Bernstein apresentou um estudo revolucionário, onde demonstrou que a redução progressiva ou "congelamento" dos graus de liberdade supérfluos podia tornar a dinâmica do movimento humano mais estável e consistente (BERNSTEIN, 1967). Perante estas evidências, convém referir que só a interação que se estabelece entre os vários ossos que compõem o nosso esqueleto resulta em 244 graus de liberdade. Para além disso, a movimentação de um membro superior numa tarefa como tocar violino ou lançar o dardo no atletismo exige, ao nível articular, o controlo de sete graus de liberdade, sendo que, se for 
analisado do ponto de vista muscular, o número de graus de liberdade deste segmento corporal aumenta para 26 combinações possíveis (ROSE, 1997; ZATSIORSKY, 1998).

No entanto, embora a teorização de BERNSTEIN (1967) seja verdadeiramente inovadora para o estudo da coordenação e controlo do movimento humano, autores como NEWELL e VAILLANCOURT (2001) e TANI (2005) defendem que os graus de liberdade estão dependentes das caraterísticas, complexidade e objetivo das tarefas. Por exemplo, ao observarmos o ato de tocar bateria, que é bastante complexo e exige grande coordenação motora em simultâneo dos membros superiores e inferiores, não podemos afirmar, de forma robusta, que o aumento ou a diminuição dos graus sejam benéficos ou prejudiciais para a ação do executante. Provavelmente, ao contrário de habilidades desportivas, podemos sim especular que a diminuição de graus de liberdade em tarefas desta natureza pode não ajudar o executante no controlo e coordenação motora, uma vez que a sua criatividade pode ser "limitada", influenciando negativamente o potencial artístico e a capacidade de improvisação do baterista.

Face ao exposto, suportados no estudo de OLIVEIRA e SHIM (2008), apresentamos um conjunto de dúvidas/questões que são transversais à aprendizagem e ao desempenho de habilidades musicais e desportivas, nomeadamente:

1. Quantas unidades motoras devem ser recrutadas pelo sistema nervoso central e quais as frequências necessárias para produzir a ativação muscular de uma determinada habilidade musical ou desportiva?

2. Como é que o sistema nervoso central seleciona e realiza combinações articulares para executar uma determinada habilidade musical ou desportiva?

3. O que significa efetuar escolhas ao nível do controlo motor na execução de uma determinada habilidade musical ou desportiva?

4. A existência de infinitas possibilidades de escolha na execução de uma determinada habilidade musical ou desportiva não poderá levar ao aumento da variabilidade ("ruído") no sistema motor?

Neste contexto, OLIVEIRA e SHIM (2008) indicam que os graus de liberdade redundantes podem ser necessários para o sistema nervoso central estabilizar ou desestabilizar variáveis 
consideradas relevantes para a realização de uma determinada tarefa. Dito de outro modo, a diminuição dos graus de liberdade, entenda-se, no contexto da execução de um determinado movimento, sugere apenas uma redução do esforço do sistema nervoso central face a um problema motor, sendo que, pode não o eliminar por completo.

\section{3 - "Constranger" para aprender}

O modelo de NEWELL (1986) mostra que os "constrangimentos" ou "restrições", que limitam, positivamente, a regulação e dinâmica do movimento humano, não devem ser encarados como uma influência negativa do comportamento, mas sim como um conjunto de limitações que podem influenciar o sistema de ação (ARAÚJO, 2006).

Deste modo, ao verificar que os constrangimentos exerciam influência na dinâmica da resposta do movimento humano, NEWELL (1986) classificou-os em três categorias que se relacionam com as caraterísticas dos praticantes, do envolvimento e da tarefa, descrevendo a Abordagem Baseada com base nos Constrangimentos (ABC):

1. As caraterísticas do praticante: estão relacionadas com as suas capacidades físicas, psicológicas, funcionais, entre outras;

2. Os constrangimentos do envolvimento: reportam-se aos aspetos físicos, ambientais e sociais;

3. Os constrangimentos da tarefa: referem-se às caraterísticas, complexidade, dificuldade, especificidade, regras e objetivos.

O modelo de NEWELL (1986) demonstra que o comportamento resulta da interação que ocorre entre praticante, envolvimento e tarefa. Neste sentido, a dinâmica que se estabelece entre os constrangimentos é um fator a ter em conta, uma vez que cada categoria pode não conseguir per si influenciar o desempenho ou execução motora (ARAÚJO, 2006; DIAS, COUCEIRO, BARREIROS, CLEMENTE, MENDES, MARTINS, 2014).

Posto isto, ao relacionarmos os constrangimentos de NEWELL (1986) com o desempenho de habilidades desportivas e musicais, verifica-se que as caraterísticas morfológicas dos 
executantes (peso, altura e estatura) e funcionais (motivação, fadiga, entre outras) podem condicionar a força, aceleração, velocidade de execução e amplitude do movimento ao longo da performance (DIAS, COUCEIRO, BARREIROS, CLEMENTE, MENDES, MARTINS, 2014). Estes aspectos dizem respeito aos perfis individuais que distinguem cada praticante no processo de execução motora. Por exemplo, se déssemos a mesma bateria a diferentes bateristas que executam estilos musicais distintos (Rock, Jazz ou Pop) para tocar a mesma música, entenda-se, sem recorrer à leitura de uma pauta musical, a sua forma de tocar e de interpretar a música seria - provavelmente - diferenciada de praticante para praticante em função do seu estilo musical. O mesmo se passaria, por exemplo, na análise do desempenho motor de jogadores profissionais de futebol pertencentes à mesma equipa (laterais, atacantes e guarda-redes), quando lhes fosse solicitada a tarefa de rematar à baliza perante diferentes ângulos de remate. Neste caso, presumivelmente, cada jogador teria diferentes formas de rematar, imprimindo mais ou menos efeito com o pé na bola; usando a parte interna ou externa do pé; efetuando o remate mais afastado ou mais perto da bola, algo que tornaria o desempenho motor e o resultado final da ação distinto de jogador para jogador.

Por seu lado, as irregularidades que o envolvimento oferece, podem constranger o executante a ajustar a sua técnica para vencer as restrições impostas na tarefa. Assim, quando um baterista de Rock é solicitado para tocar $J a z z$, tem que se ajustar a um novo estilo musical que desconhece, ou que pelo menos não está habituado a desempenhar com tanta frequência. O mesmo se passa com o jogador de futebol, que "atua" em vários campos, e se adapta a diversos relvados, diferentes públicos e condições atmosféricas distintas.

Além disso, o baterista pode ser constrangido a atuar em locais fechados, ou seja, concertos em bares, salas de espectáculos, gravações em estúdio, e perante grandes multidões (concertos ao vivo, tais como o Woodstock). Neste caso, o baterista tem que controlar e coordenar este movimento perante diferentes contextos sem afetar a sua performance. Estes aspetos são análogos a alguns desportos realizados indoor (basquetebol, voleibol, andebol ou futsal), onde os seus praticantes têm que se adaptar às condições do piso, temperatura, público, entre outros constrangimentos. 
Considerando uma nova situação, o baterista também pode tocar com outros kits de bateria que não os seus e executar músicas que não conhece e/ou nunca executou. Desta forma, tendo em conta que o modelo de constrangimentos de NEWELL (1986) apresenta um tipo de informação específica que está interligada por várias componentes (praticante, tarefa e envolvimento), poder-se-á dizer que existe um contexto definido para a ação onde um determinado músico tem que encontrar várias soluções para resolver um problema motor (ARAÚJO, 2006; DIAS, COUCEIRO, BARREIROS, CLEMENTE, MENDES, MARTINS, 2014). Também aqui, de ponto de vista desportivo, cabe o exemplo de um jogador de ténis que treina com outras raquetas e bolas que não as suas, tendo que se adaptar às caraterísticas de diferentes materiais e manter um nível de performance adequado.

\section{4 - Cognição, ação ou criatividade?}

A aprendizagem de um determinado instrumento musical é algo que exige elevado controlo motor e uma grande coordenação de movimentos, os quais podem requerer apenas a intervenção dos membros superiores (tocar saxofone) ou a conjugação, em simultâneo, dos membros superiores com os membros inferiores (tocar bateria). Nesta base, é plausível que a prática musical envolva atividade cognitiva e o cérebro assuma, neste caso, o seu papel no controlo e coordenação deste tipo de habilidades. Para tal, a reação a estímulos sonoros, o tempo e cadência musical parecem ser muito importantes nesta vertente, acrescendo ainda os aspetos relacionados com a visão, memorização, atenção, interpretação e a criatividade dos executantes (LAGE, BORÉM, BENDA, MORAES, 2002). Estas vertentes são análogas à prática de alguns movimentos desportivos (e.g., natação sincronizada), onde se exige grande coordenação e controlo motor por parte dos seus praticantes.

É do senso comum que o corpo humano tem à sua disposição uma gama quase ilimitada de movimentos, conseguindo escolher através de um comando central (cérebro ou sistema nervoso central), aqueles, que mais se adequam às tarefas a desempenhar. Porém, a variabilidade intrínseca aos sistemas de movimento humano permite-nos considerar que a 
coordenação de todos os músculos e articulações do corpo humano não é apenas da responsabilidade do sistema nervoso central, englobando outras componentes que são designadas na literatura como sinergias funcionais ou estruturas coordenativas. Estas estruturas constrangem o sistema motor a efectuar ações em função das caraterísticas das mesmas e não, presumivelmente, de acordo com qualquer plano estabelecido centralmente (GODINHO, BARREIROS, PEZARAT-CORREIA, 1998; DIAS, MENDES, MENDES, 2013).

Nesta linha de pensamento, TURVEY, FITCH e TULLER (1982) defendem que as estruturas coordenativas podem atuar como uma unidade funcional de produção de movimento e contribuir para a coordenação e controlo dos graus de liberdade. Por seu lado Turvey (1990) descreve as estruturas coordenativas como um grupo de músculos dotados de alguma autonomia e independência durante a realização de movimento, assumindo funções semelhantes a um programa motor (DIAS, MENDES, MENDES, 2013). Contudo, também neste reduto, à semelhança da análise de movimentos desportivos, pouco se sabe do papel destas estruturas no contexto da aprendizagem e prática musical.

Além disso, tal como nas habilidades desportivas, a aprendizagem e desempenho de habilidades musicais parecem não depender exclusivamente da ação do sistema nervoso central, sendo necessário ter em conta outros aspetos, tais como a plasticidade cerebral, os padrões de variabilidade dos ritmos endógenos da frequência cardíaca dos executantes e os ritmos respiratórios. Não obstante, todos estes pressupostos merecem um trabalho multidisciplinar aprofundado, que envolva músicos, neurologistas, entre outros intervenientes, emergindo assim novas evidências científicas que corroborem a multiplicidade de experiências musicais, lúdicas, criativas emergentes neste âmbito (LAGE, BORÉM, BENDA, MORAES, 2002).

Posto isto, voltamos novamente ao exemplo de tocar bateria para continuar a descrever o papel das estruturas internas (cérebro ou memória) no controlo do movimento humano. Deste modo, quando o baterista está a tocar num ensaio ou concerto, não pensa em todos os passos que vai efetuar para agir. Além do mais, mesmo perante uma pauta, que contém todas as notas musicais necessárias à orientação da sua aprendizagem/desempenho, o ato de tocar 
sai naturalmente, ou seja, como se o corpo atuasse sem ser comandado centralmente. Por outras palavras, o baterista "auto-organiza" o seu comportamento motor sem ter um "maestro" a comandar superiormente o movimento.

Estes argumentos encontram paralelismo em desportos como o Golfe, onde o jogador bate com o taco na bola sem pensar na forma como executa o movimento e sem memorizar ou determinar previamente a velocidade, aceleração e amplitude para ter sucesso na ação. Na realidade, esta "informação contextual” é fornecida através das caraterísticas do envolvimento, tais como: estado do green, condições atmosféricas, entre outras fontes relevantes externas ao executante, fazendo com que o golfista se adapte às condições e aos constrangimentos/restrições que encontra no treino ou competição (DIAS, COUCEIRO, BARREIROS, CLEMENTE, MENDES, MARTINS, 2014).

Para além da componente cognitiva, tanto em habilidades desportivas como musicais, é preciso ainda ter em conta os aspetos relacionados com coordenação intramuscular e intermuscular, a idade do executante, a sua capacidade de adaptação e reorganização motora, assim como a fadiga que emerge da prática. Nesta base, importa não só analisar estas variáveis de forma isolada, mas também em conjunto, de modo a perceber os seus efeitos na aprendizagem e performance deste tipo de movimentos (SCHMIDT, WRISBERG, 2001, TANI, 2005).

Neste reduto, um outro aspeto que tem merecido particular atenção na área do Comportamento Motor diz respeito ao tipo de informação que um executante consegue reter na memória durante o controlo e coordenação de movimentos (LAGE, BORÉM, VIEIRA, BARREIROS, 2007). Estas dúvidas têm vindo a suscitar a atenção de vários investigadores na análise de movimentos desportivos, questionando a validade das representações mentais como veículo privilegiado na produção de movimentos (TANI, 2005). Deste modo, ao afinarmos pelos argumentos dos apologistas da Teoria dos Sistemas Dinâmicos, os quais defendem que o indivíduo tem a capacidade de auto-organizar o seu desempenho sem recorrer a processos cognitivos elaborados, consideramos que cada executante pode ser encarado como um sistema -não-linear- que consegue, presumivelmente, regular o seu 
comportamento motor em diferentes contextos, estando sujeito a vários estímulos e constrangimentos que são impossíveis de prever por antecipação à ação (ARAÚJO, 2006). Numa outra perspetiva, JOURDAIN (1998) demonstrou que a performance musical exige uma sinergia entre cognição, ação e criatividade. Nesta linha de pensamento, outros estudos (MUSZKAT, CORREIA, CAMPOS, 2000; PERETZ, ZATORRE, 2005) seguiram as mesmas premissas e assumiram que a música tem, efetivamente, uma função muito importante na atividade cerebral, principalmente no aumento da conectividade das sinapses entre neurónios.

Por seu lado, através dos apologistas da abordagem ecológica (ARÁUJO, 2006; DIAS, COUCEIRO, BARREIROS, CLEMENTE, MENDES, MARTINS, 2014), os quais defendem que a informação necessária para ter sucesso na ação está presente no ambiente, não necessitando assim de recorrer a processos cognitivos elaborados, constata-se que a coordenação e controlo de movimentos associados à música e ao desporto não dependem, exclusivamente, de programas motores que se confinam no sistema nervoso central, pois o executante pode percecionar diretamente a informação necessária para realizar uma tarefa, isto sem ter de recorrer às estruturas hierárquicas. Tal como refere o ARAÚJO (2006), é na ação que o executante resolve os seus problemas motores e atua em função daquilo que o contexto lhe reclama. Isto demonstra que as "informações" estão disponíveis no "ambiente" e tanto os músicos como os desportistas podem detetar e usar as mesmas rumo ao objetivo da tarefa, não necessitando, porém, de transportar toda a informação nas "suas cabeças". Referimo-nos, em concreto, à ação do executante que está embutida num contexto específico de performance, a qual não pode ser encarada como um mero "ato cognitivo", mas antes como uma relação direta emergente entre executante e envolvimento (ARAÚJO, 2006; DIAS, COUCEIRO, BARREIROS, CLEMENTE, MENDES, MARTINS, 2014).

Deste modo, tanto o músico como o desportista podem detetar as fontes de informação relevantes para alcançar o objetivo da tarefa, não sendo necessário memorizar a execução de um movimento ou padrão "ideal”, pré-concebido. Assim, não é aconselhável "afinar" e “calibrar" o executante para realizar comportamentos "estereotipados", mas antes privilegiar o saber fazer - autonomamente (NEWELL, 1986). Contudo, não obstante esta informação, ainda não se sabe, exatamente, como é que esta "afinação" e "calibração" do movimento é 
efetuada, por exemplo, na performance da música erudita, a qual abrange um conjunto de variáveis mais alargado do que outras vertentes musicais. Perante este quadro teórico, a maioria da informação que o executante retira durante a aprendizagem e desempenho de habilidades desportivas e musicais parece resultar, essencialmente, da perceção de informações externas, nomeadamente: visuais, auditivas, sensoriais, entre outras (ARAÚJO, 2006).

Outro fator importante neste contexto prende-se com a "criatividade", enquanto processo emergente na aprendizagem ou desempenho de movimentos. Esta capacidade de realizar um movimento novo e inesperado, mas que é adequado na matriz de desempenho de um determinado instrumento e não foge ao padrão de afinação musical regularmente instituído, é algo que pode ser avaliado por especialistas na matéria (e.g., júri de uma audição para recrutar guitarristas ou bateristas). Aqui é importante ressalvar que criatividade não é o mesmo que improvisação, pois este último termo refere-se ao cenário propício à criatividade e não pode ser visto como um processo em si mesmo (CORREIA, BARREIROS, PASSOS, 2013).

Face ao exposto, o comportamento adaptativo tanto na música como no desporto, em vez de ser importado através do cérebro, parece resultar da confluência de um conjunto constrangimentos/restrições sob as condições limitadas de uma tarefa ou objetivo específíco. Deste modo, ao contrário das teorias de perceção indirecta (ADAMS, 1971; SCHMIDT, 1975), o executante da música ou do desporto obtém per si as propriedades significativas do envolvimento sem ter de utilizar mediadores internos. Neste caso, é o contexto que reclama a aprendizagem e desempenho do executante (ARAÚJO, 2006), como por exemplo, as sensações transmitidas pelo público num concerto ou num estádio de futebol, o palco onde atua ou o pavilhão onde joga, as condições de luminosidade a temperatura do pavilhão ou do espaço do concerto musical que é realizado ao ar livre, entre outras informações contextuais. 


\section{5 - Praticar para aprender}

Tal como em movimentos desportivos, também em habilidades musicais é necessário determinar a "quantidade" de prática a ministrar durante o processo de aprendizagem. Alguns destes pressupostos estão documentados nos estudos de ERICSSON e SMITH (1991), ERICSSON, KRAMPE, TESCH-ROMER (1993) e ERICSSON e LEHMANN (1996), onde os autores demonstraram, através de um fenómeno designado por prática deliberada, que a quantidade absoluta de prática é indispensável para atingir um determinado nível de expertise, dando o exemplo da regra das 10.000 horas ou dos 10 anos de prática na execução de instrumentos como o violino. Importa referir que estamos perante um processo estruturado e sistemático que envolve ativamente o executante, sendo este norteado por objetivos exequíveis e realistas, normalmente organizados por um tutor. Todavia, não obstante estas considerações, salientamos que a prática deliberada diz-nos pouco sobre a forma como o aprendiz se adapta às caraterísticas e exigências da tarefa, pois, como verificámos anteriormente, cada indivíduo responde de forma diferente aos estímulos do envolvimento e a aprendizagem e o desempenho não podem ser encarados como um processo linear (CORREIA, BARREIROS, PASSOS, 2013).

Outro aspecto importante neste contexto é o fato de muitos executantes começarem o seu percurso musical ou desportivo inseridos em ambientes familiares onde alguns membros executam ou já executaram algum instrumento, bem como alguma modalidade desportiva. Por exemplo, o pai de Wolfgang Amadeus Mozart era um violinista famoso e experiente que dedicou grande parte da sua carreira à educação musical do filho. Isto mostra que é necessário aprofundar outras variáveis que não apenas a quantidade de prática ou a prática deliberada - por si mesma - na aprendizagem ou desempenho de um determinado instrumento. Além disso, tanto nas habilidades musicais como desportivas, é fundamental ter em conta que a capacidade e o ritmo de aprendizagem podem variar significativamente de executante para executante em função das suas caraterísticas, assim como, também, da capacidade em adquirir, reter e transferir informação (MAGILL, 2011). 
Por seu lado, para músicos ou desportistas experts que já dominam uma determinada habilidade, a prática realizada sob condições de estabilidade necessita de ser "quebrada", de modo a continuar a existir evolução motora (cf. modelo de "não-equilíbrio" de TANI, 2005). Para melhor compreendermos estes argumentos, tomemos novamente como exemplo o baterista que está habituado a tocar Jazz e, de um momento para o outro, é contratado para integrar uma banda de Rock. Neste caso, o executante terá que se adaptar a um novo contexto que implica uma ruptura ("não-equilíbrio") com as condições estáveis ("equilíbrio") que controlavam o seu espetro de ação. Por outras palavras, a capacidade deste baterista se manter nesta banda estará "dependente" na forma como este adquire, retém e transfere informação para os seus pares e a transmite através do seu desempenho motor. Para tal, a sua capacidade de adaptação e auto-organização ao longo do ato de tocar bateria permitirlhe-á (ou não) ser bem sucedido na tarefa. O mesmo se passa no contexto desportivo com um jogador de futebol, que é constrangido a jogar e assumir uma posição no campo a que não está habituado, por exemplo, passar de atacante para lateral, sendo que este executante terá que se ajustar aos constrangimentos que resultam da "nova tarefa".

\section{6 - Conclusão}

A coordenação e o controlo de movimentos associados à música permitem compreender melhor o papel dos graus de liberdade na aprendizagem e desempenho de habilidades motoras desportivas e vice-versa. Assim, é importante perceber se o excesso de graus de liberdade atua na compensação de sinergias entre os vários elementos que compõem o sistema motor, ou se, por outro lado, potenciam mais dificuldades no funcionamento desse mesmo sistema.

A música e o desporto podem contribuir, decisivamente, para aprofundar a área do Comportamento Motor no âmbito dos sistemas de movimento humano. Estas duas vertentes, ainda que distintas, retratam muito bem como os seus executantes percecionam as possibilidades de ação do seu corpo e as usam para controlar movimentos. Deste modo, é plausível que a fluidez deste tipo de ações motoras não resulte, exclusivamente, do processamento de informação que tem lugar no sistema nervoso central sob a forma de representação mental do movimento. 
A variabilidade intrínseca aos sistemas de movimento humano indica que a coordenação e controlo de movimentos desportivos e musicais emergem essencialmente da ação do executante, da tarefa e do envolvimento onde esta tem lugar. Deste modo, conceitos como prática deliberada, criatividade e improvisação devem ser mais aprofundados, isto na música e no desporto.

Tanto o músico como o desportista podem adaptar-se à enorme variabilidade de ações que o contexto lhe proporciona se vivenciarem um maior número de experiências motoras que não sejam previsíveis ou estandardizadas. Deste modo, indo ao encontro de ARAÚJO (2006), consideramos que a díade executante-contexto deve ser estimulada na aprendizagem e desempenho de movimentos, motivando, assim, a descoberta ativa de soluções que potenciem os graus de liberdade onde atuam diferentes sistemas de acção.

Finalmente, considerando que esta revisão foi essencialmente direcionada para um conjunto de estilos musicais específicos, nomeadamente: Jazz, Pop e Rock, algo que constitui uma limitação deste artigo, urge aprofundar, futuramente, de que forma a coordenação e controlo de habilidades musicais emerge, por exemplo, no contexto da música erudita, e de que modo pode ser estabelecida uma relação com a aprendizagem e desempenho de música popular e de outras habilidades desportivas.

\section{Referências}

1. ADAMS, J.A. (1971). “A closed-loop theory of motor learning”. Journal of Motor Behaviour. v.3, n.2, p.111-150.

2. ARAÚJO, D. (2006). Tomada de decisão no desporto. Lisboa: Edições FMH.

3. BERNSTEIN, N. (1967). The coordination and regulation of movements. Oxford: Pergamon. 
4. CORREIA, N.; BARREIROS, B.; PASSOS, P. (2013). Comportamento motor e criatividade na aprendizagem da música - o caso do Jazz. In Comportamento motor, controlo e aprendizagem. Ed. Pedro Passos, Lisboa: Edições FMH. p.215-234.

5. DIAS, G.; MENDES, P.; MENDES, R. (2013). "Modelos explicativos do controlo motor na aprendizagem e treino de movimentos desportivos". Annals of Research in Sport and Physical Activity. v.4, n.4, p.9-20.

6. DIAS, G.; COUCEIRO, M.S.; BARREIROS, J.; CLEMENTE, F.; MENDES, R.; MARTINS, F. (2014). "Distance and Slope Constraints: Adaptation and Variability in Golf Putting”. Motor Control. v.18, p.221-243.

7. ERICSSON, K.A.; LEHMANN, A.C. (1996). "Expert and exceptional performance: Evidence of maximal adaptation to task constraints". Annual review of psychology. v.47, p.273-305.

8. ERICSSON, K.A.; SMITH, J. (1991). Toward a general theory of expertise. New York: Cambridge University Press.

9. ERICSSON, K.A.; KRAMPE, R.T.; TESCH-ROMER, C. (1993). "The role of deliberate practice in the acquisition of expert performance". American psychological association. v.100, p.363-406.

10. GODINHO, M., BARREIROS, J.; PEZARAT-CORREIA, P. (1998). Aprendizagem Motora: teorias e modelos. Lisboa: Edições FMH.

11. JOURDAIN, R. (1998). Música, Cérebro e Êxtase. Rio de Janeiro: Objetiva.

12. LAGE, G.M.; BORÉM, F.; BENDA, R.N.; MORAES, L.C. (2002). “Aprendizagem motora na performance musical: reflexões sobre conceitos e aplicabilidade". Per Musi: Belo Horizonte. v.5, p.14-37.

13. LAGE, G.M.; BORÉM, F.; VIEIRA, M.N.; BARREIROS, J. (2007). "Visual and Tactile Information in Double Bass Intonation Control". Motor Control. v.11, p.151-165.

14. MAGILL, R.A. (2011). Motor learning and control: concepts and applications. New York: McGraw-Hill. 
15. MUSZKAT, M.; CORREIA, C.M.F.; CAMPOS, S.M. (2000). "Música e neurociências". Revista de Neurociências. v.8, n.2, p.70-75.

16. NEWELL, K. M. (1986). Constraints on the Development of Coordination. In Motor Development in Children: Aspects of Coordination and Control. Ed. M. Wade; H.T.A. Whiting. Dordrecht: Martinus Nijhoff, p.341-360.

17. NEWELL, K.M.; VAILLANCOURT, D.E. (2001). "Dimensional change in motor learning”. Human Movement Science. v.20, n.4, p.695-715.

18. OLIVEIRA, M.A.; SHIM, J.K. (2008). "Redundância motora: o problema de graus de liberdade na ciência do movimento humano". Revista Brasileira de Ciência do Esporte. v. 29, n.2, p.9-25.

19. PALMER, C. (2006). The nature of memory for music performance skills. In E. Altenmüller, M. Wiesendanger, \& J. Kesselring (Ed), Music, motor control and the brain. Oxford, UK: Oxford University Press, pp. 39-53.

20. PERETZ, I.; ZATORRE, R. (2005). “Brain organization for music processing”. Annual Review of Psychology. v.56, p.90-114.

21. ROSE, D. (1997). A multilevel approach to the study of motor learning and control. Boston: Allyn \& Bacon.

22. SCHMIDT, R.; WRISBERG, C.A. (2001). Aprendizagem e performance motora: uma abordagem baseada no problema. Porto Alegre: Artmed.

23. SCHMIDT, R.A. (1975). "A schema theory of discrete motor skill learning". Psychological Review. v.82, n.4, p.225-260.

24. TANI, G. (2005). Comportamento motor. Aprendizagem e desenvolvimento. Rio de Janeiro: Guanabara Koogan.

25. TURVEY, M.T. (1990). “Coordination”. American Psychologist. v.45, n.8, p.938-953.

26. TURVEY, M.T., FITCH, H.L.; TULLER, B. (1982). The Bernstein perspective I: the problems of degree of freedom and context-conditioned variability. In: Kelso JA 
(ed.). Human motor behavior: an introduction. Hillsdale, NJ: Lawrence Erlbaum Asociates, p.132-143.

27. ZATSIORSKY, V.M. (1998). Kinematics of Human Motion. Illinois: Human Kinetics Publishers.

Notas sobre o autor

Gonçalo Dias é Doutor, Mestre e Pós-graduado em Ciências do Desporto pela Faculdade de Ciências do Desporto e Educação Física da Universidade de Coimbra (FCDEF.UC); Licenciado em Educação Física pela Escola Superior de Educação de Coimbra (ESEC/IPC); Professor Convidado na Faculdade de Ciências de Desporto e Educação Física da Universidade de Coimbra; Professor Convidado na Escola Superior de Educação de Coimbra - Instituto Politécnico de Coimbra; Investigador do CIDAF / FCDEF.UC; Membro do Conselho Científico da Faculdade de Ciências de Desporto e Educação Física da Universidade de Coimbra; Autor de vários livros e artigos científicos sobre Controlo Motor e Treino Desportivo; Músico (vocalista e baterista) profissional com vários trabalhos publicados. 